\title{
KINTSUGI URBANO EN LA AVENIDA DEL FERROCARRIL. IBAGUÉ, COLOMBIA (1921-1970)
}

\author{
Andrés Francel \\ Universidad del Tolima \\ aefranceld@ut.edu.co
}

\section{RESUMEN}

La avenida del ferrocarril de la ciudad de lbagué comunica la zona antigua con la moderna y el sector comercial con el sector de servicios. Esta comunicación es también una separación, caracterizada por las diferencias topográficas y la carencia de elementos que estimulen el tejido social. La fragmentación que se genera a su alrededor contiene la pauperización del espacio urbano y arquitectónico, por lo cual se constituye en el motivo de estudio que busca presentar soluciones a partir de la comprensión de las dimensiones espaciales que se involucran en su desarrollo histórico. Consecuentemente, se analizan los factores de segregación espacial derivados de la interacción entre el paisaje natural y el urbano para presentar posibles soluciones mediante una analogía metodológica con el Kintsugi o reparación de los daños para su reconversión en una nueva pieza ética y estética.

Palabras Clave: Historia Urbana, Corredor Vial, Fragmento Urbano, Zona Residual

\begin{abstract}
The railroad avenue communicates the old city with the modern and the commercial with the services sector. This communication is also a separation, characterized by the topographical differences and the lack of elements that stimulate the social fabric. The fragmentation generated around it contains the pauperization of urban and architectural space, which is why it is the study motive that seeks to present solutions based on the understanding of the spatial dimensions that are involved in its historical development. Consequently, the spatial segregation factors derived from the interaction between the natural and the urban landscape are analyzed to present possible solutions according to the methodology of the Kintsugi or repair of the damages for its reconversion in a new ethic and aesthetic piece.
\end{abstract}

Key Words: Urban History, Road Corridor, Urban Fragment, Residual Zone 


\section{PRESENTACIÓN DE LA ANALOGÍA}

Hablar de Kintsugi y ciudad implica el uso de la analogía como instrumento para acceder al conocimiento y a la solución de problemas desde las funciones poéticas (I Soler, 2006). La analogía permite que dos imágenes se toquen y generen una tercera con un nuevo sentido. En este caso, el estudio de la ciudad se compara con el kintsugi, técnica japonesa de reconstrucción de piezas cerámicas rotas mediante laca urushi, cuya costura se resalta principalmente con oro (Hammill, 2016). Esta comparación implica comprender la ciudad como una pieza cerámica (artística y artesanal) que ha sido rota o fragmentada y también recompuesta con diversos grados de acierto. Si actualmente queremos analizar esa fragmentación y proponer algunos modelos para su reconstrucción, es necesario identificar los fragmentos para recomponer la pieza cerámica-urbana y procurar que la costura evidencie tanto la fragmentación como su reconstrucción, lo cual genera posibles modelos de intervención urbanística en condiciones de respeto por la historia de la ciudad, cuyo último fin es la unión entre la ética y la estética del ejercicio del arquitecto.

Esta analogía es una consecuencia del estudio de la historia urbanística y arquitectónica de la ciudad de lbagué, en la cual se han identificado rupturas, fragmentación, segregación, cicatrización y costuras urbanas que constituyen testimonios de las estrategias que se han implementado para intervenir la ciudad. Su análisis conduce al cuestionamiento de las políticas urbanas, de la fractura entre los niveles gubernamentales nacional y local y la inercia del desarrollo urbano como resultado de la libre intervención del entorno construido.

\section{PRESENTACIÓN GENERAL}

Ibagué es una ciudad intermedia con una población de 500.000 habitantes, situada en el centro de Colombia. Es la capital del departamento del Tolima desde 1887, condición que la articuló directamente con los principios del desarrollo nacional basado en la infraestructura ferroviaria para conectar las principales ciudades del interior con la costa atlántica para promover la exportación mediante el puerto de Barranquilla Figura 1. Las obras de infraestructura ferroviaria culminaron con la construcción de la Estación Pedro Nel Ospina en 1928, momento desde el cual la ciudad se acopló al trazado realizado por el gobierno nacional, sin que mediaran planes urbanísticos que generaran coherencias entre la vía férrea y la extensión de la malla urbana, lo cual presenta diversas características morfológicas, topográficas, de segregación espacial y de posibilidades de reinterpretación que serán abordadas en este estudio. 


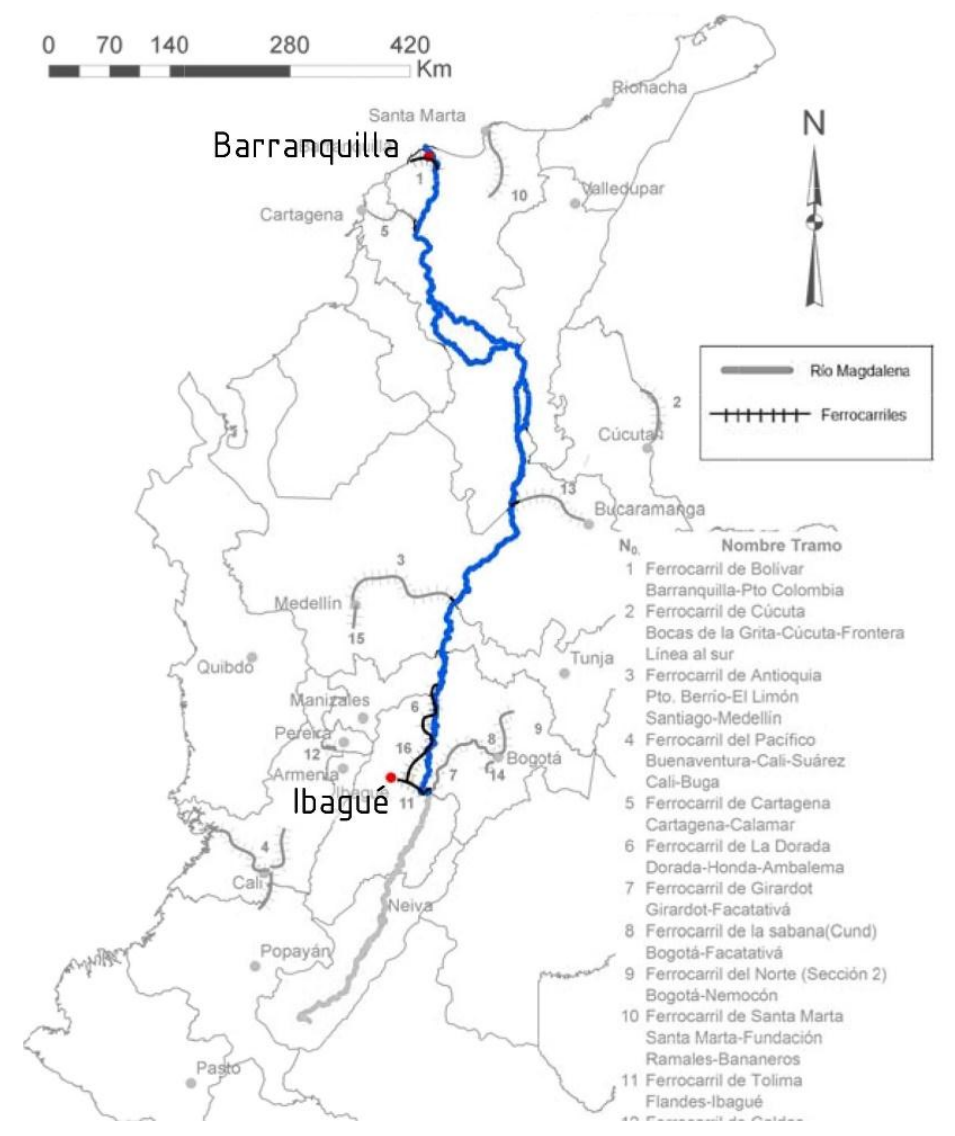

Figura 1. Ferrocarriles de Colombia en 1925.

Fuente: (Meisel Roca, Ramírez, \& Jaramillo, 2014, pág. 26)

En 1987 la estación del ferrocarril fue demolida para construir el terminal de transportes y la vía férrea se transformó en la avenida del ferrocarril para uso automotriz. Un recorrido habitual por la avenida del ferrocarril permite observar que la ciudad está fragmentada de acuerdo con el trazado de la línea del ferrocarril, la cual separó las clases sociales, los usos y el paisaje. Al observar los planos urbanos, las morfologías residuales son evidentes y la dirección de la avenida es anómala, de acuerdo con la retícula colonial que se extendió hasta mediados del siglo XX.

Estas características permiten clasificarla como una cicatriz urbana, reforzada por proyectos urbanos que no han interpretado el corazón del problema y que, en términos de esta investigación, evidencia la superposición de las políticas nacionales de desarrollo sobre la incipiente planeación local, lo cual significa una debilidad de las instancias articuladoras entre los grandes principios nacionales y las sosegadas dinámicas locales. Como consecuencia, se realizó un análisis sobre los factores de segregación espacial derivados de la interacción entre el paisaje y los instrumentos de planeación implementados para presentar posibles soluciones de acuerdo con la metodología del kintsugi o reparación de los daños para su reconversión en una nueva pieza estética.

\section{METODOLOGÍA}

Al identificar la desarticulación entre la malla urbana y la avenida del ferrocarril, se propuso la caracterización de cada uno de los fragmentos situados a los largo de la avenida con el propósito de tener un conocimiento suficiente para su posterior recomposición en el kintsugi. Para ello, se abordó el estudio de fragmentos desde una dimensión histórica, que condujo a la búsqueda de la cartografía en diversas entidades locales como el archivo histórico municipal, la biblioteca Darío Echandía del banco de la República y la planoteca de planeación municipal. El análisis de esta cartografía permitió determinar las relaciones temporales entre la avenida y los desarrollos 
inmobiliarios a su alrededor. Los planos encontrados a partir de los cuales se puede determinar esta interacción, son los de 1942, 1948, 1958 y luego una serie de heliografías entre 1970 y 1993, hasta el plano digital en sistemas CAD de 2005, luego del cual es mayor la disponibilidad de documentos digitales

Figura 2.
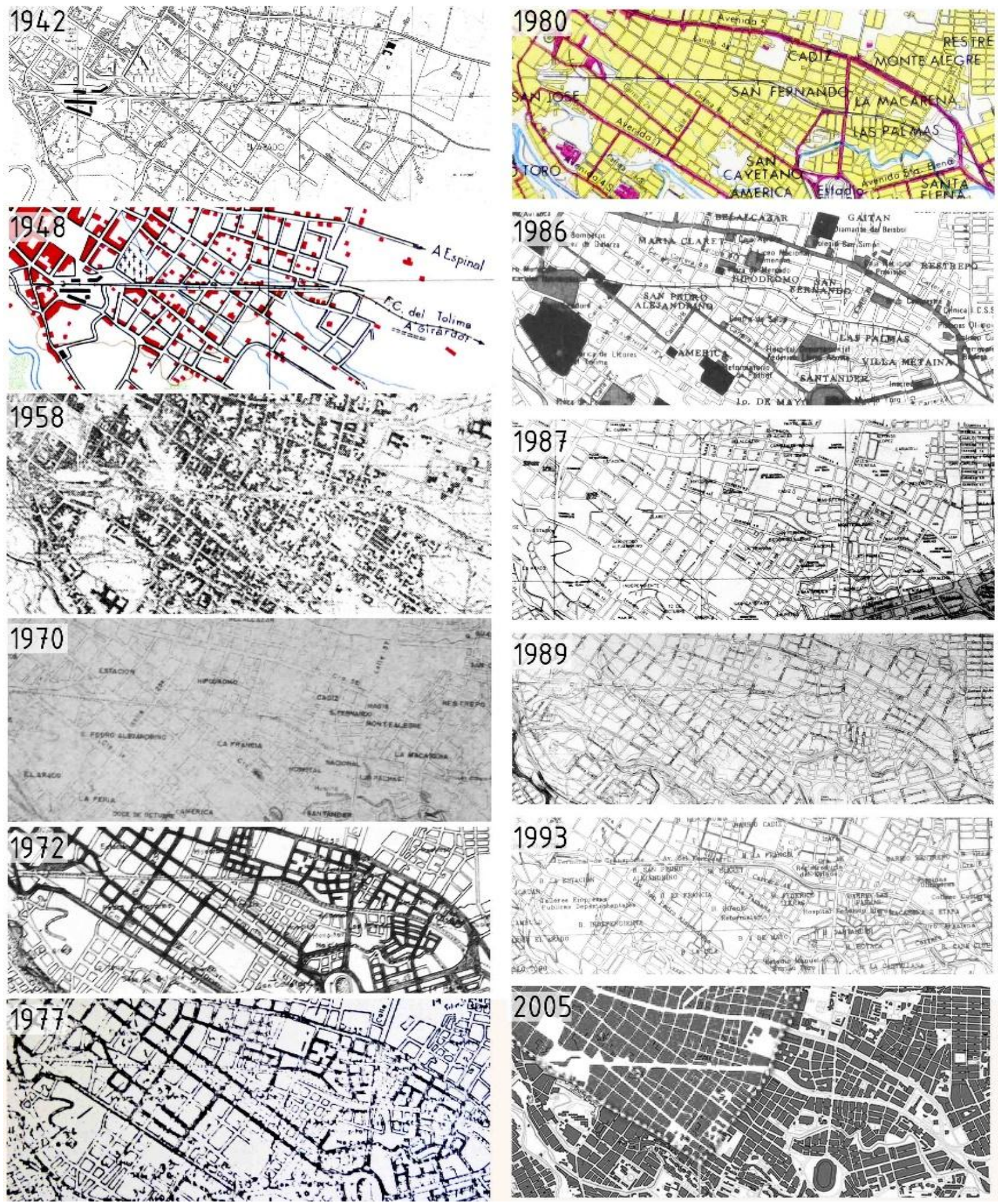

Figura 2. Evolución de la zona de estudio en la cartografía histórica.

Elaboración propia (2016) a partir de los planos hallados en la biblioteca Darío Echandía del banco de la República. 
El segundo componente es el de espacialización de los fragmentos, lo cual significa capturar relaciones de ambas márgenes de la avenida del ferrocarril mediante fotografías para establecer continuidades de paisaje. En ellas se vinculan la homogeneidad de las construcciones, sus condiciones materiales, la continuidad del espacio público y la vegetación. Luego se relacionaron estas fotografías con los perfiles topográficos generados a partir de los datos obtenidos en google earth, vectorizados y editados en Photoshop. De este modo se obtuvo una sectorización primaria correspondiente con una topografía cultural o las relaciones entre las características del terreno y las expresiones urbanísticas y arquitectónicas.

El tercer componente fue el análisis de morfologías para determinar los fragmentos generados a nivel geométrico. Esta clasificación se derivó del estudio de la cartografía histórica y permite establecer relaciones directas entre la geometría del crecimiento urbano y las continuidades a lo largo de la vía férrea en sus dos márgenes norte y sur. En este punto se determinaron cinco morfologías y se realizaron las observaciones consecuentes entre formas urbanas y condiciones socio-económicas básicas. Las coincidencias entre el análisis de morfologías y la espacialización de fragmentos evidenciaron la cicatriz o costura que debía realizarse en la avenida.

El cuarto componente consistió en la operatización de la analogía del kintsugi urbano. Para ello, se realizaron propuestas sobre cómo generar la costura entre los fragmentos identificados, de acuerdo con las características descritas en cada uno de los apartados temáticos. De este modo, al final de trabajo se encuentra una descripción con el gráfico para la intervención de la avenida del ferrocarril que sintetiza la investigación realizada.

Los resultados del trabajo pretenden aportar una posibilidad para la interpretación de los fenómenos urbanos desde la generación de principios que ayuden a la solución de problemas similares en las ciudades intermedias contemporáneas que implementan normativas nacionales desarticuladas del desarrollo local. Además, procura brindar un sustrato teórico y práctico para que el estudio de la ciudad y las propuestas que se realicen en el futuro, incorporen un contenido estético en directa relación con la ética arquitectónica. En consecuencia, se presentan a continuación los fragmentos identificados en la zona estudiada, de acuerdo con las categorías de análisis que se encontraron durante el proceso de investigación.

\section{GENERALIDAD DE LA FRAGMENTACIÓN}

La avenida del ferrocarril se extiende tres kilómetros, entre la calle 19 al occidente, y la 43 al oriente. Hacia el occidente remata en el actual terminal de transportes y hacia el oriente desemboca en el viaducto del SENA (Servicio Nacional de Aprendizaje). Su extensión corresponde con diversas situaciones y momentos de la ciudad. Por ejemplo, la calle 19 es el límite de la ciudad antigua y la calle 42 es el inicio de la ciudad moderna. El trazado de la ciudad antigua tiene una inclinación de 35 grados geométricos, oblicua a la ciudad moderna con 10 grados de inclinación. Entre las dos está la avenida del ferrocarril, con un trazado horizontal de occidente a oriente Figura 3. 


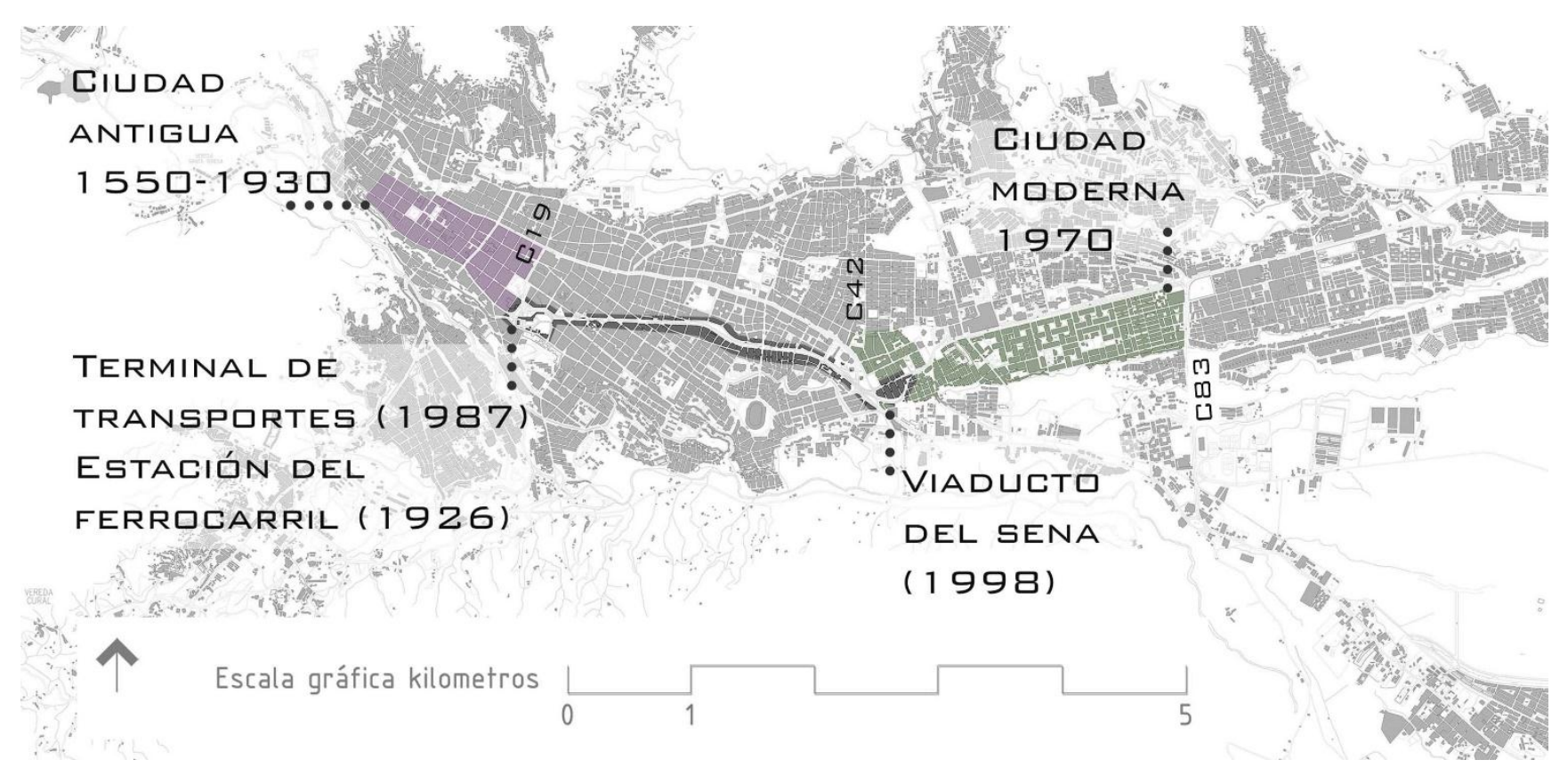

Figura 3. Localización de la avenida del ferrocarril y su relación con la ciudad antigua y la moderna. Elaboración propia (2016).

\section{SÍNTESIS HISTÓRICA DE LA FRAGMENTACIÓN}

La vías férreas arribaron a lbagué en 1921 (Patiño, 1990) y la estación ferroviaria correspondiente se construyó en 1926 (Martínez Silva, 2003, pág. 149; Ortiz Vidales, 2003, pág. 367; Gutiérrez, 1921, pág. 387). A partir de aquel momento, la ciudad se extendió a su alrededor sin normas de planeamiento urbano, lo cual se evidencia en la autorización, posterior suspensión y reaprobación para la urbanización de los predios adyacentes a la estación del ferrocarril (Francel, 2013a, pág. 125). Estas circunstancias de oscilación en las decisiones municipales están directamente ligadas con la intersección y superposición de dos procesos. El primero de ellos fue la política nacional infraestructural cuyo símbolo fue la interconexión a través de los ferrocarriles (Arango, 1989). El segundo de ellos fue el crecimiento rutinario de la ciudad de acuerdo con los patrones coloniales de retícula hipodámica que se fueron flexibilizando en la medida en que el gobierno local controlaba menos los fenómenos urbanísticos y los delegaba en el libre mercado inmobiliario (Francel, 2017).

Para atenuar la división generada por las líneas del ferrocarril, se plantearon en 1935 tres pasos a desnivel para vincular vehicularmente las dos márgenes de la actual avenida (Francel, 2017). Estos pasos no se construyeron ni quedan planos en los cuales se pueda verificar su localización, por lo cual se realizó su restitución a partir de las descripciones presentes en documento escrito del Plan Urbanístico Ibagué Futuro (Sociedad Industrial de Ingeniería y Construcciones (SIDEICO), 1935). Luego de ubicarlos, se realizó la restitución del paisaje fluvial de la ciudad, a partir del cual se identificaron algunas quebradas que actualmente son imperceptibles por su canalización subterránea. Como resultado, se identificó que los pasos planteados por el plan urbanístico lbagué Futuro coinciden con los lugares en que las fuentes hídricas se intersecaban con la vía férrea. Esto significa que el plan de 1935 planteó la canalización de las fuentes hídricas para aprovechar sus depresiones como corredores viales y parques lineales que interconectaran la ciudad, dejando las líneas del ferrocarril elevadas. Los pasos a desnivel intentaron solucionar un problema evidente desde el trazado de la línea del ferrocarril, consistente en la división de la ciudad entre sur y norte entre las calles 19 y 25, hasta donde se extendía lbagué cuando arribaron las vías del ferrocarril y se construyó la estación. Este límite urbanístico se encuentra una cuadra a la derecha del segundo paso a desnivel, correspondiente a la quebrada El Sillón

Figura 4. 


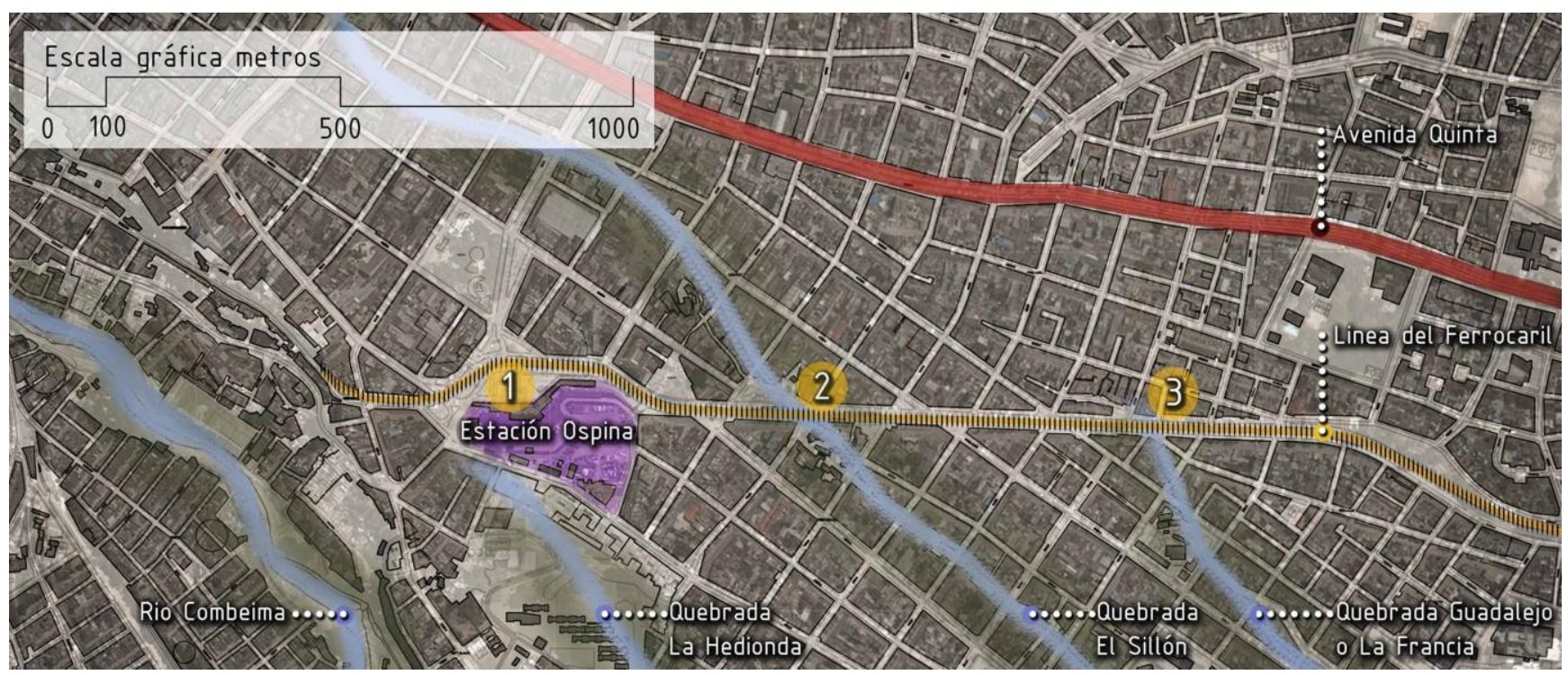

Figura 4. Relación entre la traza urbana, las fuentes hídricas y la línea del ferrocarril. Elaborado por José Alejandro Ojeda (2016).

A partir de la década de 1950, la infraestructura ferroviaria decayó como consecuencia del desarrollo automotriz, de modo que la vía férrea se convirtió en un corredor residual, abandonado y sin tránsito vehicular de ningún tipo, para cuya solución se propuso su conversión en avenida del ferrocarril, la cual quedó consignada en el plan piloto de 1966 (Martinez Silva, 2016). Sin embargo, el deterioro de la vía férrea continúo hasta la construcción de la avenida en 1993. Durante este lapso, la ciudad se expandió indiferente a las líneas férreas, con múltiples consecuencias. La primera es que la orientación del trazado urbano persistió de acuerdo con el patrón colonial, como una inercia de desarrollo urbano, lo cual revela la ausencia de un plan para articular las líneas del ferrocarril con el trazado urbano. La segunda consecuencia fue que la ciudad se extendió hacia el sur de las líneas férreas que inicialmente marcaban el límite urbanístico, lo cual condujo al refuerzo de la desconexión de las márgenes sur y norte de la ciudad, acentuando la anomalía compositiva de la vía férrea. A lo largo de esta anomalía se generaron cuadras triangulares residuales. Estas características geométricas se relacionan directamente con la topografía, pues la retícula urbana fue trazada en paralelo con la dirección de las fuentes hídricas, mientras que la vía férrea fue indiferente a la topografía originaria como resultado de la dominación del paisaje mediante la ingeniería

Figura 4.

Para el desarrollo de los IX Juegos Deportivos Nacionales en 1970, se generó un nuevo sector de ciudad desde la calle 42 hasta la 83 (Comité organizador de los IX Juegos Nacionales, 1970). En la 42 se ubicó el coliseo para deportes de salón, las piscinas olímpicas y la villa deportiva o conjunto residencial para alojar las diversas delegaciones que posteriormente se convirtió en el barrio Metaima, en el cual se implementaron los desarrollos de la vivienda multifamiliar. En este sector de ciudad se implementaron los principios del movimiento moderno en su segunda fase, caracterizada por una madurez formal y conceptual con enfoques institucionales que beneficiaron el desarrollo de vivienda y equipamientos (Francel, 2013b). La ruptura con la traza herdada de la colonia es evidente a partir de la calle 42 hacia el oriente, del modo en que se observa en la

Figura 3.

\section{ESPACIALIZACIÓN DE LOS FRAGMENTOS}

A partir de las condiciones presentes en la fragmentación histórica, se observó una clara división social, de modo que hacia el norte de la avenida del ferrocarril, con una mayor elevación topográfica, se ubican barrios para las clases medias y altas, mientras que hacia el sur de la avenida los desarrollos inmobiliarios tienen orígenes más humildes (Delgado, 2006). Al profundizar en esta observación, se identificaron los siguientes tramos: 1) Desde la 
calle 19 hasta la 23 existe una zona degradada que se caracteriza por la presencia de bodegas, zonas de carga y descarga, hoteles y restaurantes rudimentarios, comercio sexual y abundancia de habitantes de calle, producto del impacto conjunto de las dinámicas de la estación del ferrocarril construida en 1926 y la plaza de mercado construida en 1958. 2) Entre las calles 23 y 28 se observa el crecimiento orgánico de las clases menos favorecidas en la zona de expansión de lbagué desde 1935 hasta 1958 con uso residencial principalmente, lo cual dota de homogeneidad a la zona, en la cual las viviendas se han adaptado al crecimiento comercial posterior a la creación de la avenida. 3) Entre las calles 28 y 37 se presenta la mayor diferencia socioeconómica, derivada de la topografía y la zonificación, consistente en un sector elevado hacia el norte, en el cual se construyeron viviendas para los trabajadores del sector público y las clases medias entre 1958 y 1966 . Hacia el sur se encuentra el piedemonte, en el cual se desarrollaron barrios populares simultáneamente, en lo que se observan los principios de zonificación planteados en 1935 y 1966. 4) Entre las calles 37 y 40 las diferencias socioeconómicas son menores, al igual que la pendiente del terreno. En este sector se dio un crecimiento detonado por el estadio a partir de su construcción en 1958. 5) Entre las calles 40 y el viaducto del SENA, las clases sociales y la topografía se homogenizan en reciprocidad con los instrumentos de planeación de 1970 que corresponden con la designación de Ibagué como sede de los IX Juegos Deportivos Nacionales

Figura 5.

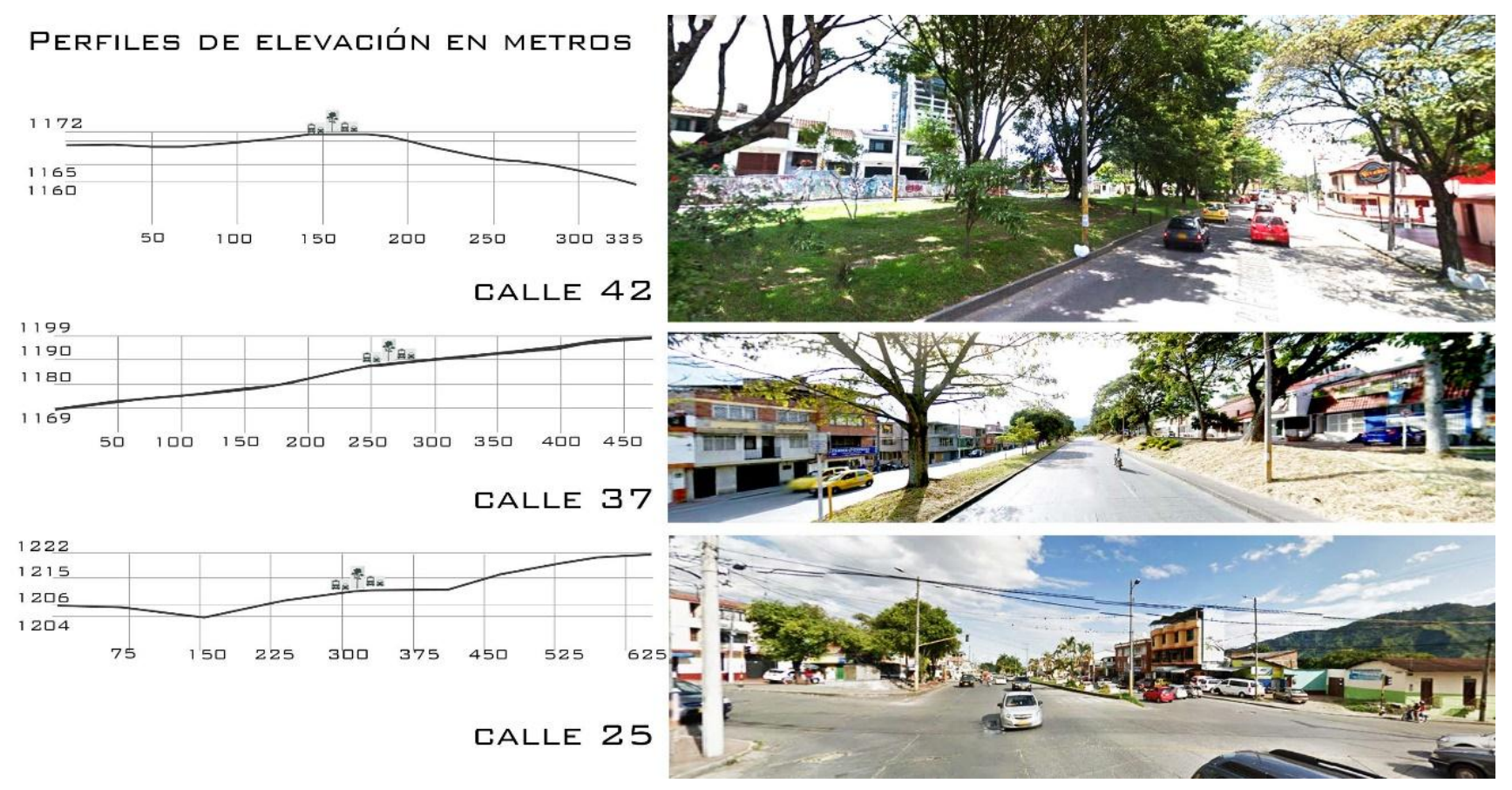

Figura 5. Perfiles topográficos y panorámicas de la avenida del ferrocarril.

Elaboración propia (2017).

\section{INTERPRETACIÓN DE LAS MORFOLOGÍAS FRAGMENTARIAS}

La forma urbana, como resultado material de la acción humana, permite rastrear las ideas y los procesos que la originaron (Benjamin, 1962) y comprender el "registro arquitectónico [...] como un producto más de la cultura material y un mecanismo formal de reproducción de los sistemas sociales" (Mañana-Borrazás, Blanco-Rotea, \& Ayán Vila, 2002). De este modo, las relaciones entre el componente formal y el mental dejan capas o vestigios cuyo estudio se puede realizar a partir del concepto de lo arqueotectónico, que significa el uso de componentes metodológicos y categorías de análisis en las cuales convergen la arqueología, la historia y la arquitectura, como la estratigrafía no invasiva, es decir, el análisis de capas superpuestas del pasado que permite analizar una edificación por encima del nivel del suelo (o cota cero) sin excavarla (Moreno Martín, 2014). 
El proceso consistió en identificar las formas urbanas inmediatas a la avenida del ferrocarril. Las dos primeras corresponden a elementos fragmentados alrededor de los remates de la vía: el terminal en la calle 19 y el viaducto del SENA en la calle 43. Las otras tres revelan los procesos de interacción de las manzanas con la avenida. A cada forma se asignó un número, comenzando por la zona alrededor del terminal de transportes, construido en 1987 en el lugar que ocupó la estación del ferrocarril (Terminal de Transportes de Ibagué S.A., 2015) y finalizando en el viaducto del SENA, construido en 1998 (Construtec S.A.S., 2017)

Figura 6.

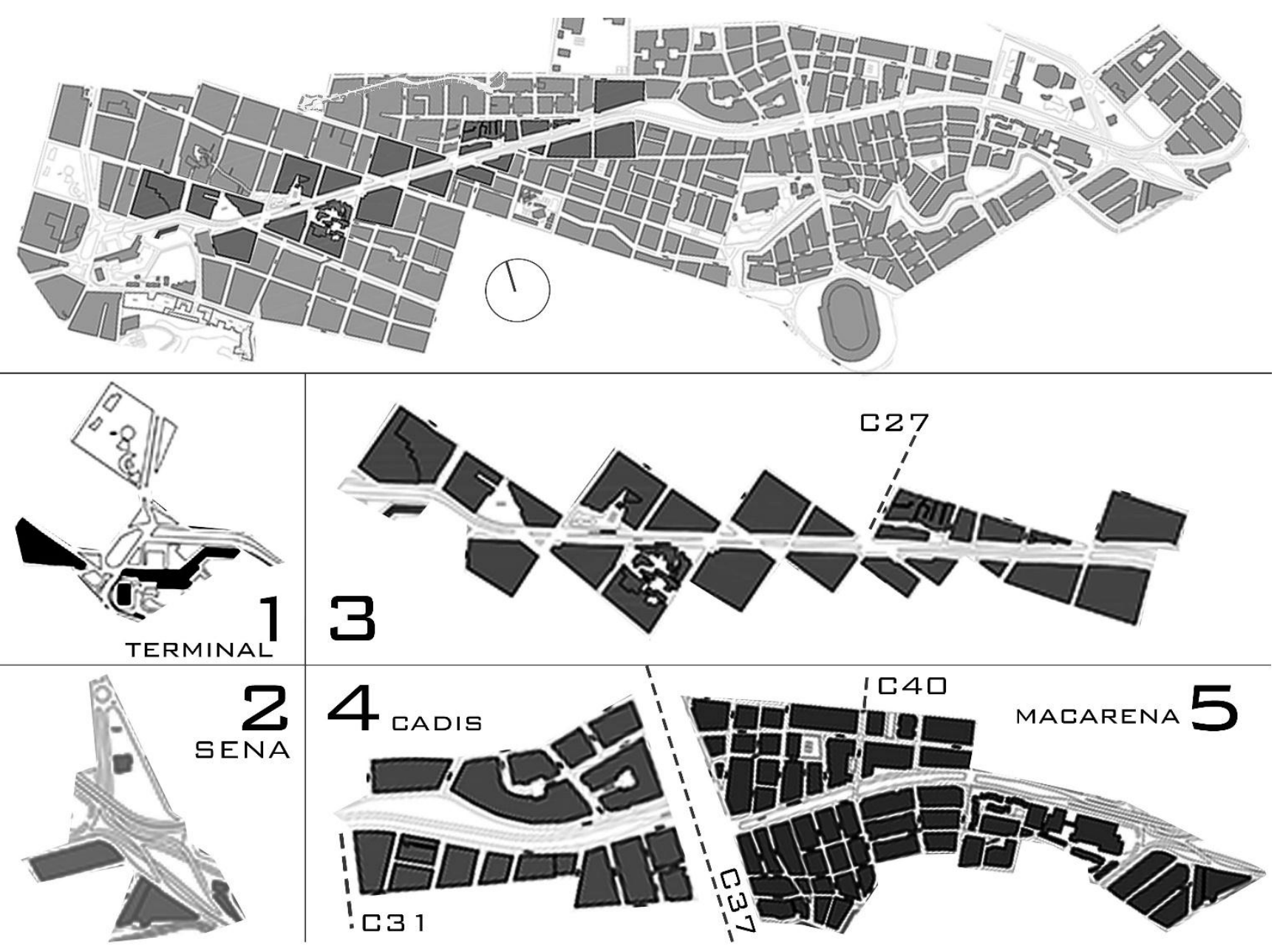

Figura 6. Morfologías y fragmentación.

Elaboración propia (2017)

La primera morfología presenta en la Figura 6 es producto del Plan Piloto de 1966, que privilegió el componente vial automovilístico de la ciudad con el propósito de interpretar la vocación de la ciudad como nodo comercial entre las principales ciudades del país (Martinez Silva, 2016). La fragmentación está compuesta por formas geométricas claras y racionales que caracterizaron al movimiento moderno (Benevolo, 1963). Es evidente, en esta fragmentación, que el paradigma de desarrollo de las ciudades consistió en aquel momento en la generación de grandes equipamientos y vías que pudiesen detonar transformaciones sociales y el progreso material (Almandoz, 2007).

La segunda morfología corresponde con la resolución de los problemas viales urbanos a través de la ingeniería (Tino Ramos, 2007). El conflicto generado en este lugar consiste en la intersección de las antiguas vías del ferrocarril que conducía a Bogotá y la carrera 5, antiguo camino real a Santafé, actualmente avenida Mirolindo 
(Francel, 2015). A ellas se sumó el trazado de la avenida el Jordán que delimitó por el norte la expansión de la ciudad en 1970 y la doble calzada de la carrera 4 Estadio. El intercambio vial generó un puente que conecta la avenida del ferrocarril con la avenida el Jordán, un paso a desnivel que conecta la avenida Mirolindo con la carrera 4 Estadio y un paso a nivel que vincula la carrera 5, la avenida ferrocarril y la avenida el Mlrolindo. Los efectos de la fragmentación tienen mayores dimensiones como consecuencia de las vías involucradas, de las capacidades técnicas de la época y del presupuesto asignado. La consecuencia es la acentuación del aislamiento entre las dos márgenes del viaducto y la ausencia de espacios peatonales que se evidencia en el tejido vial sin construcciones adyacentes

Figura 6.

La tercera morfología es la superposición de la avenida del ferrocarril a la trama urbana de origen colonial. En este sector los triángulos longitudinales a la avenida generan la mayor cantidad de residuos y presentan con claridad un momento de la ciudad ausente de planeación, por lo cual no se generó un modelo de articulación entre el gran impacto vial del ferrocarril y el crecimiento inercial de la ciudad. Hacia el oriente de esta zona, a partir de la calle 27, la retícula tiene un giro mayor y las dimensiones de las cuadras son menores, lo cual revela también una ocupación del territorio regulada por principios particulares, de modo que las manzanas homogéneas que caracterizaron el periodo colonial, cedieron a un manzaneo de menores dimensiones, calles más estrechas y lotes menores.

La cuarta zona presenta un reconocimiento de la avenida en ambos costados, por lo cual las manzanas tienen formas regulares planeadas. Sin embargo, la margen norte de la avenida tiene un desarrollo orgánico en el que se observan las calles ciegas o cul de sac, mientras que hacia el sur de la avenida las manzanas conservan la inclinación de la trama colonial pero con menores dimensiones. Estas características corresponden con la identificación de grandes diferencias sociales abordadas en el apartado anterior, pues la forma vanguardista del barrio Cadis para las élites al norte de la avenida, contrastan con la repetición miniaturizada y popular al sur de la avenida.

La quinta zona se caracteriza por la desconexión de la trama con la avenida y con el resto de la ciudad. El manzaneo a ambos costados de la avenida tiene dimensiones similares pero es levemente más regular hacia el norte que hacia el sur, donde los espacios se comprimen generando trapezoides. Hacia el oriente, las manzanas tienen mayores dimensiones y las calles conectan los dos márgenes de la avenida. En este caso, la regularidad de las manzanas entre las calles 40 y 43 coincide con la homogenización de las condiciones socioeconómicas y las topográficas en el sector de la Macarena. Igualmente, las leves diferencias morfológicas a ambos costados de la avenida entre las calles 37 y 40, coinciden con las observaciones en el apartado temático anterior.

A partir de estas observaciones se afirma que la vía férrea generó zonas residuales longitudinales a su trazado, por lo cual fue clasificada como una cicatriz urbana (Xolalpa, 2015). Debido a que este término es de uso común, pero carece de especificaciones, se tomó la definición médica (Sánchez-Mateos García, Lozano Gallego, \& Sánchez Quilez, 2015) y se apropió al ámbito urbanístico, proponiendo que una cicatriz es una alteración permanente de la superficie urbana como consecuencia de un daño y se constituye en testimonio de sus reparaciones. Las alteraciones principales están representadas en el análisis morfológico. El daño fundamental ha sido la segregación socio-espacial. Las reparaciones, como se observa en la planimetría, han consistido en la rehabilitación automotriz de la vía férrea, sin que existieran propósitos de integración social.

\section{URUSHI: LA VIRTUD COMO RESINA PARA REPARAR LOS FRAGMENTOS}

Luego de identificar los fragmentos alrededor de la vía férrea, es necesario abordar la cicatriz, la sucesión de costuras para recomponer la forma de la pieza cerámica urbana final. Este ejercicio permite el reconocimiento de los elementos que conforman la resina (o urushi) que servirá como fluido adhesivo para reunir coherentemente los fragmentos. En consecuencia, es una práctica de la virtud, un respeto por lo existente luego de reconocer las lesiones presentes en cada uno de los trozos en que se ha roto durante la historia.

La avenida del ferrocarril tiene la ventaja esencial de una suave pendiente que permite un descansado tránsito peatonal y ciclista, característica poco común en Ibagué debido a su topografía montañosa. Por este motivo ha sido incluida como la segunda opción para implementar el plan de bicicarriles para la ciudad. La primera es la 
carrera 5 debido a su importancia comercial. La ausencia e irregularidad de los andenes impide que el tránsito peatonal sea eficiente en la avenida del ferrocarril. Sin embargo, la mayor diversidad socioeconómica en sus márgenes, como se ha expresado en los apartados anteriores, permite comprender la importancia de proyectarla como un eje de desarrollo e integración.

El primer factor de suave topografía conduce a que la generación de andenes y bicicarriles sea más económica y más atractiva. La abundancia de zonas residuales o demarcaciones con "dispersión de tipologías, dimensiones y categorías" (Cirer-Costa, 2011, pág. 12) permite imaginar la integración de estos espacios a través del concepto de parques de bolsillo o parques vecinales cuya extensión es menor a 3500 metros cuadrados (Molina Prieto, 2006). El camino para que esta integración vecinal sea exitosa consiste en enfocarse en la relación directa entre el espacio público como núcleo de participación ciudadana, cuyos beneficios garanticen la apropiación, definida como la acción que articula el territorio (Talero Rodríguez, 2013). La metodología ideal para el desarrollo de estos procesos, consecuentemente, es el diseño participativo para garantizar que las actividades deportivas o culturales representen a todos los grupos y géneros poblacionales y aumenten su capacidad de participación continua, organizada, transparente y responsable (Fernández, 2014).

A esta reconversión de los espacios residuales en parques vecinales mediante la participación ciudadana, debe sumarse la vocacional de la vía analizada. Uno de los caminos es su comprensión como corredor ambiental urbano, en el cual abundan los "parches vegetales" (Romero, Toledo, Órdenes, \& Vásquez, 2001). Este potencial ambiental es una consecuencia de la acción conjunta del aislamiento de las viviendas respecto de las vías del ferrocarril, la topografía que obligó la generación de taludes con alto componente vegetal, la tradición local de beneficiar el desarrollo de árboles de alto porte en los separadores viales y las características geográficas de la ciudad en medio del bosque húmedo tropical. Además, como se observa en la Figura 4, la avenida del ferrocarril se superpone a tres fuentes hídricas, la Hedionda, el Sillón y Guadalejo, por lo cual su enfoque debería testimoniar esta interacción entre la naturaleza, el paisaje y las obras civiles, reforzando su proyección como mirador sobre la depresión hacia el río Combeima con el cerro de la Martinica como plano de fondo. Estas características permiten pensar en la avenida del ferrocarril como un parque lineal que conecta tres quebradas con el paisaje circundante para propiciar la interacción social (Forero Sanclemente \& Bueno García, 2015). 


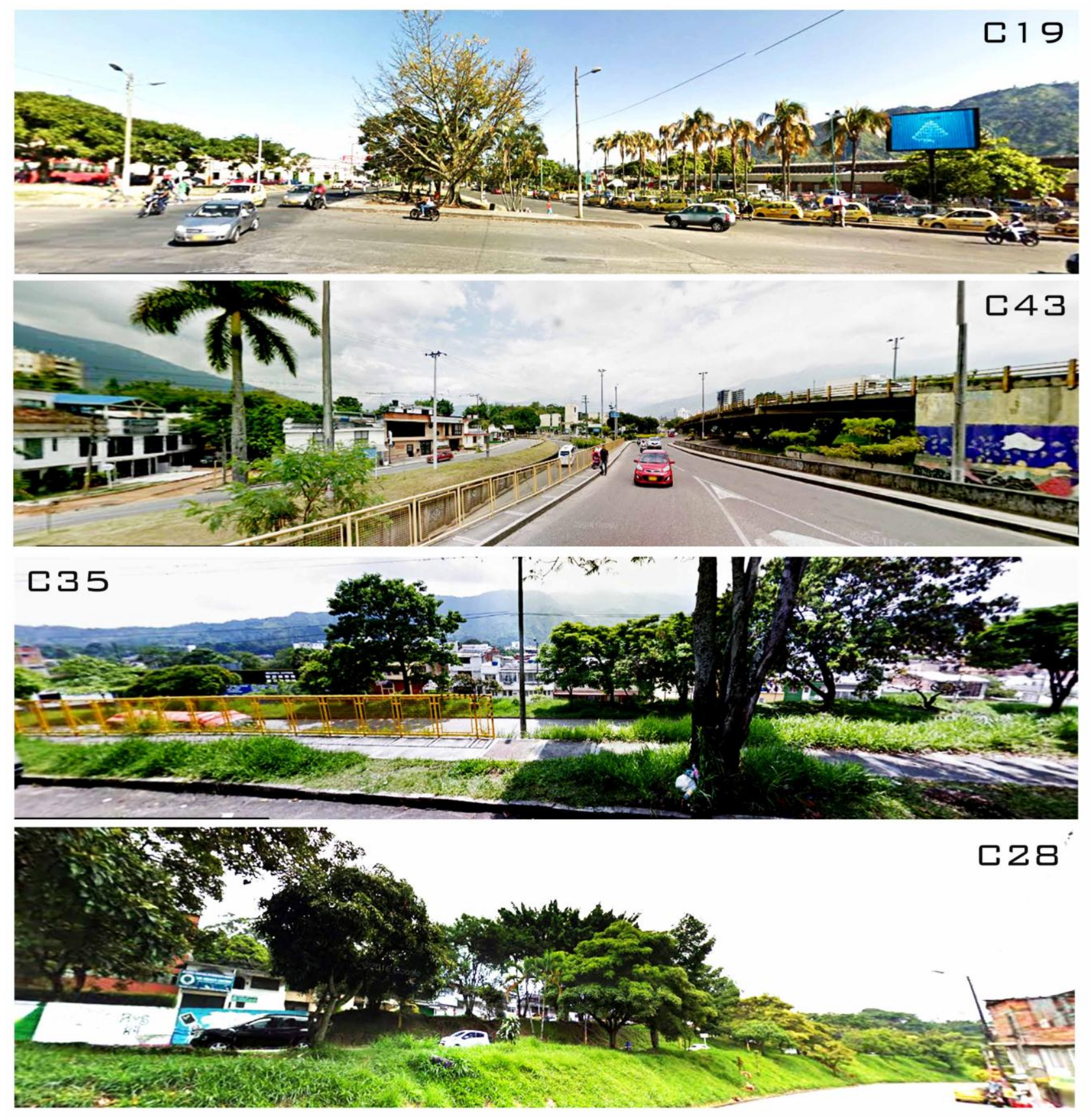

Figura 7. Fragmentación viaria y continuidad ambiental.

Elaboración propia (2017)

Parte de esta lectura del territorio se realizó en 1935 con el plan urbanístico lbagué Futuro, en el marco del cual se propuso la relación paisajística entre la carrera 5 como mirador sobre la quebrada el Sillón, actualmente canalizada y que corresponde con el trazado de la carrera 4, la cual se interseca con la avenida del ferrocarril en la calle 26 (Honorable Concejo Municipal, 1935). Es importante reiterar que para 1935 existía la vía férrea, sus márgenes no estaban urbanizadas y las fuentes hídricas no estaban canalizadas, por lo cual la apreciación del paisaje natural era mayor y la presencia de las líneas ferroviarias obligó la nivelación del terreno en medio de la ladera que separa Cadis de la Francia. La indecisión del gobierno municipal para implementar este plan y la polémica sobre su diseño (González Calle, 2006) condujo a la urbanización de las zonas proyectadas como bosques y jardines de la quebrada el Sillón e impidió la creación de la avenida del Café. Sin embargo, las 
dimensiones de la avenida del ferrocarril permitieron la generación y conservación de su corredor ambiental, por lo cual el espíritu del plan de 1935 pervive a pesar de que no fuera implementado

Figura 8.

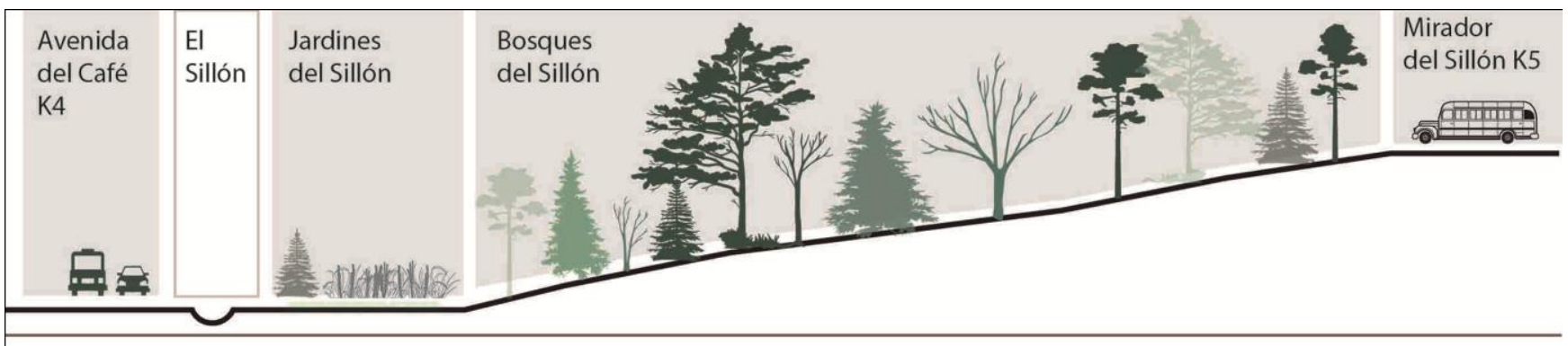

Figura 8. Paisaje del Sillón según las descripciones del plan urbanístico Ibagué Futuro de 1935.

Elaboración propia (2016)

En las indecisiones sobre la implementación del plan de 1935, se encuentra una explicación para la morfología de la margen sur de la avenida del ferrocarril, pues aprovechando el "bello panorama de las orillas de El Combeima" (Sociedad Industrial de Ingeniería y Construcciones (SIDEICO), 1935, pág. 66), se planteó que esta zona se destinara para los campos deportivos de los cuales carecía Ibagué. En aquel momento se planteó un hipódromo, campos de tenis, básquetbol, piscinas y lago para deportes de remo. Se aconsejó el contrato inmediato del proyecto de la zona deportiva de acuerdo con un plan que incluyera la siembra de árboles en las zonas señaladas para bosques naturales con el fin de evitar contratiempos, consistentes en la ocupación de los terrenos por otros usos sin planeación. Sin embargo, los campos fueron ocupados legalmente con intervenciones urbanísticas destinadas a la vivienda obrera que caracteriza la zona entre la estación del ferrocarril (actualmente terminar de transportes) y el nuevo cementerio (actualmente San Bonifacio). Finalmente, los campos deportivos hubiesen generado la tensión necesaria entre la avenida del ferrocarril y el río Combeima para facilitar la integración de las dos márgenes de la vía.

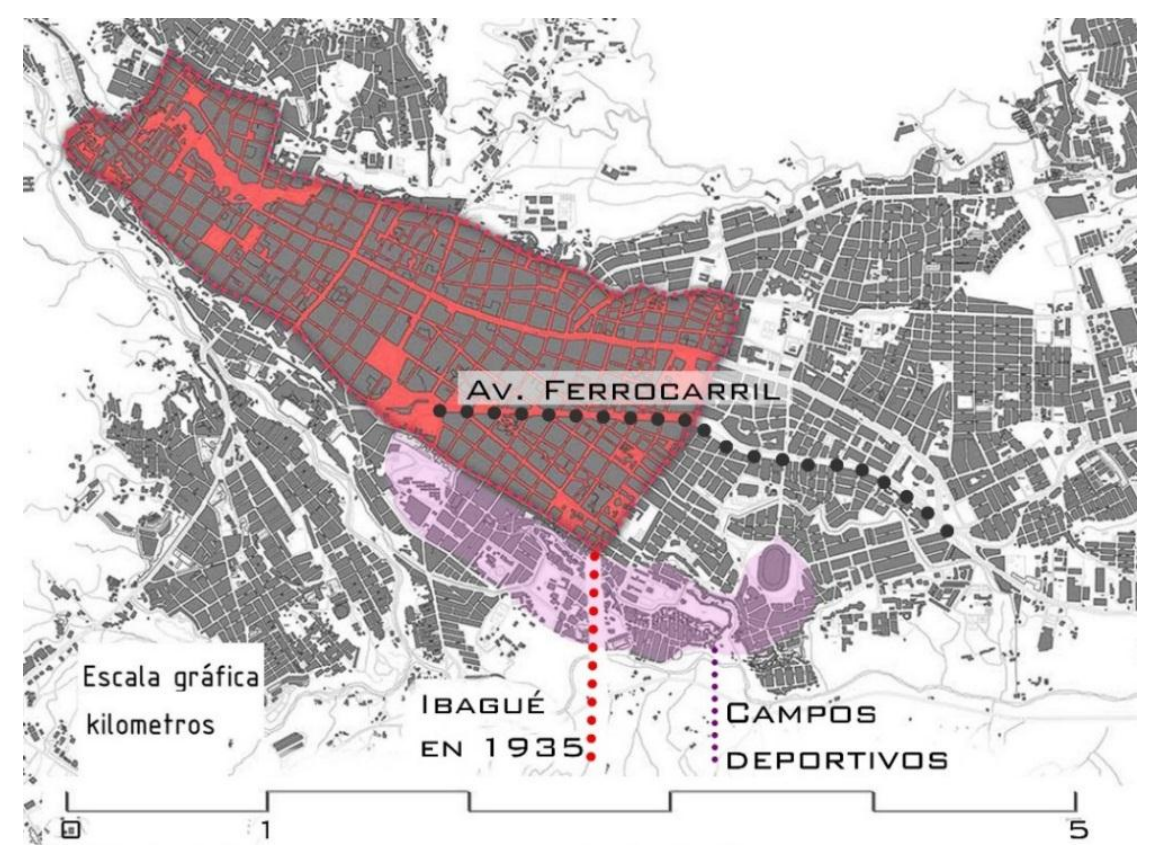

Figura 9. Localización de los campos deportivos en relación con la ciudad en 1935 y la ciudad actual. Elaboración propia (2017) 
Del planteamiento original de los campos deportivos, queda el estadio Manuel Murillo Toro, originalmente denominado centro deportivo Rojas Pinilla, diseñado por Juvenal Moya Cadena y construido en 1955 (Tibaduiza Cordero, 2015). La tensión sin planificación entre el estadio y la avenida del ferrocarril, acentuó la fragmentación del trazado urbano. Sin embargo, es evidente su carácter radial puesto que en él confluyen las carreras de la ciudad antigua y las de la ciudad moderna. A esto debe sumarse la presencia del complejo deportivo de la calle 42, que deberá ser recuperado porque actualmente se encuentra en ruinas debido a la malversación de fondos para su remodelación durante los XX Juegos Deportivos Nacionales (Guarnizo, 2016). Este conjunto de circunstancias reiteran la importancia de la vocación deportiva y paisajística de la margen sur de la avenida del ferrocarril, que puede ser recuperada mediante la acción conjunta del parque lineal como corredor ambiental, las zonas peatonales, el bicicarril y la articulación de los parques vecinales.

\section{EL KINTSUGI URBANO}

En el caso de la planificación urbana, el kintsugi es un concepto del cual se apropian las ciudades postindustriales con el propósito de reparar las áreas dañadas de una ciudad, de una manera en la que se reconozca e incorpore la historia dañada del sitio (Posthuma, 2016). Este concepto permite la comprensión de la ciudad desde una relación entre la ética y la estética en la restauración y la conservación, de modo que los fenómenos urbanos como la ruina, residuo y cicatriz son manifestaciones estéticas de diversas temporalidades y por lo tanto es un deber ético su reconocimiento, respeto y preservación (Lamarque, 2016).

De acuerdo con los planteamientos de los apartados anteriores existe una resina que se encuentra en las virtudes de la avenida para reunir los fragmentos históricos, morfológicos, topográficos y sociales. El polvo de oro para revelar estas fracturas y la belleza presente en ellas, estaría compuesto por algunos principios consecuentes con las características estudiadas. Estos principios, se expresan como deberes o responsabilidades, en atención a las condiciones éticas que manifiesta el ejercicio investigativo desarrollado, lo cual significa que cada uno de los fenómenos observados requiere de soluciones que no eliminen su historia sino que recompongan su estructura final, del modo en que se expresa a continuación.

La avenida del ferrocarril debería vincular el parque López de Galarza con el terminal de transportes mediante un elemento integrador que rememorara la quebrada la Hedionda y recompusiera la fragmentación en la calle 19. EI terminal debería vincularse con la plaza de mercado de la calle 21, aprovechando el potencial gastronómico, hotelero y de bodegaje para ofrecer un panorama acogedor a quienes arriban a la terminal, para convertirla en un articulador de ciudad. La extensión de la avenida del ferrocarril entre las calles 22 y 32 requiere de la implementación de los parques de bolsillo o vecinales para aplicar una costura sobre la herida urbana (Franco Taipe, 2014), de modo que se cree un sistema de espacios de participación ciudadana a ambos costados de la avenida y permita incorporar las construcciones a la vía para una correcta territorialización. En este tramo se deberían rememorar los cauces de las quebradas el Sillón y Guadalejo o la Francia, para reforzar la importancia del corredor ambiental. Entre las calles 32 y 37, el terraceo de la vía y las zonas verdes existentes permiten desarrollar espontáneamente el mirador del barrio Cadis cuyo remate es el cerro de la Martinica. Entre las calles 37 y 40 existen dos parques cuya conexión facilitaría la integración entre las manzanas atomizadas. La fragmentación del viaducto del SENA puede solucionarse mediante la interpretación de este sector como una estación deportiva que remata la vía. La conexión entre estos elementos urbanos parece naturalmente un tren ligero, debido a la suave pendiente del terreno, de acuerdo con la explanación que se realizó hasta 1920, lo cual reduce costos de adecuación y rememora el tránsito del ferrocarril en la ciudad. Acompañando el tren, el bicicarril, la ampliación de los andenes y la siembra de árboles diversos complementan y potencian la vocación de comunicación y protección ambiental de la avenida. Las estaciones de este hipotético tren son dadas por los segmentos morfológicos, hidrográficos e institucionales que se identificaron durante el estudio. De este modo, potenciar la vocación de la avenida del ferrocarril significaría que la historia de la ciudad se recompondría desde los conceptos contemporáneos Figura 10. 


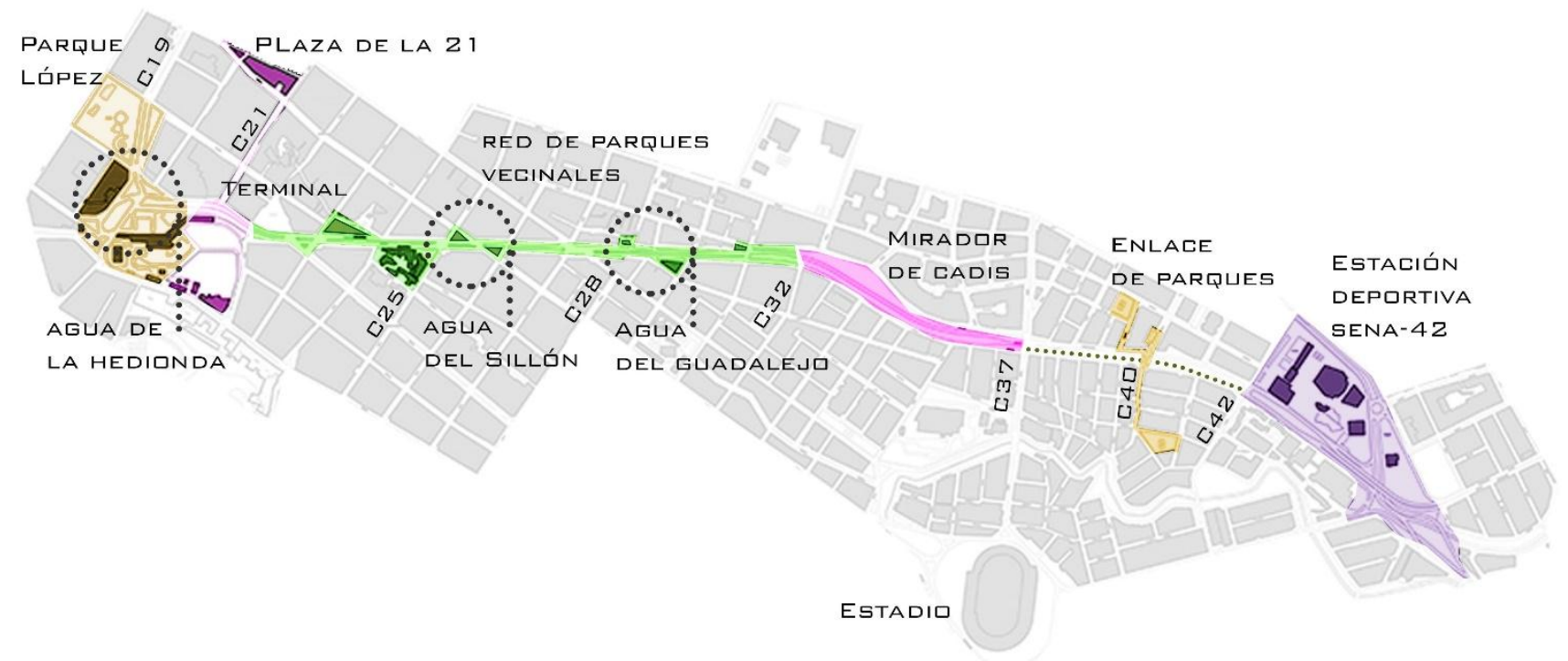

Figura 10. Kintsugi sobre la avenida del ferrocarril.

Elaboración propia (2017)

\section{UNA OBSERVACIÓN FINAL}

El kintsugi aplicado a la avenida del ferrocarril implica que antes de pensar una vía o cualquier elemento urbano desde la voluntad del diseñador, es preciso comprender los mensajes que contienen los fragmentos. En este caso de estudio, las variables abordadas de la morfología, las dinámicas socio-espaciales, geográficas, ambientales e históricas, permiten asegurar que las propuestas que se realicen en un futuro, tienen un sustrato para interpretar y respetar el entorno construido y el paisaje natural. Es obvio que existan apreciaciones opuestas sobre la belleza, la conveniencia o lo ideal del espacio que se aborda. Sin embargo, esta técnica de reconstruir una pieza rota invita a actuar responsablemente para que la intervención sea notoria y cumpla su objetivo de embellecer, respetar, preservar y crear una pieza nueva que contiene las anteriores sin destruirlas. Una analogía final es la avenida como un conjunto de vagones, cada uno de los cuales carga paisaje, agua, arquitectura y ciudadanía. Un engranaje dorado comienza a tejer una maquinaria sensata. 


\section{BIBLIOGRAFIA}

Almandoz, A. (agosto de 2007). Modernización urbanística en América Latina. Luminarias extranjeras y cambios disciplinares,1900-1960. Iberoamericana, VII(27), 59-78. Obtenido de http://www.iai.spkberlin.de/fileadmin/dokumentenbibliothek/lberoamericana/2007/27-Almandoz.pdf

Arango, S. (1989). Historia de la arquitectura en Colombia. Bogotá D.C.: Centro editorial y Facultad de Artes, Universidad Nacional de Colombia.

Benevolo, L. (1963). Historia de la arquitectura moderna. Madrid: Taurus Ediciones.

Benjamin, W. (1962). Di alcuni motivi in Baudelaire", en Angelus Novus. Torino: Einaudi.

Cirer-Costa, J. C. (30 de septiembre de 2011). Geografía fractal de un gran destino turístico. MPRA. Munich Personal RePEc Archive. Obtenido de http://mpra.ub.uni-muenchen.de/33855/

Comité organizador de los IX Juegos Nacionales. (1970). Ibagué 70 / organización de los IX Juegos Nacionales de Ibagué. Ibagué: Instituto Colombiano del Deporte.

Construtec S.A.S. (2017). Viaducto Sena. Recuperado el 15 de enero de 2017, de Página oficial de la unión temporal: http://www.constructecsa.com/index.php/gallery-categories/puentes-vehiculares/153-viaductosena

Delgado, M. (2006). Morfología urbana y conflicto social. Las medidas antigueto como políticas de dispersión de pobres. En R. Bergalli, \& I. (. Rivera Beiras, Emergencias urbanas (págs. 133-169). Barcelona: Anthropos.

Fernández, V. (enero-junio de 2014). Promoviendo un diseño urbano participativo: experiencias desde la práctica y la docencia. Revista AUS, 22-27. Recuperado el 20 de julio de 2016, de http://mingaonline.uach.cl/scielo.php?script=sci_arttext\&pid=S0718$72622014000100005 \& \operatorname{lng}=$ es\&nrm=iso\&tlng=es

Forero Sanclemente, E., \& Bueno García, L. H. (mayo de 2015). El parque lineal de palmira, un espacio dinamizador del desarrollo de la ciudad. Urbano, núm. 31, mayo, 2015, pp. (31), 64-73. Recuperado el 9 de junio de 2016, de http://184.168.109.199:8080/jspui/bitstream/123456789/7050/1/19841107006.pdf

Francel, A. (2013). Cuatro décadas de arquitectura ibaguereña (1904-1940). Ibagué: Universidad de lbagué. (2013). Historia arquitectónica de la Escuela de Cadetes de Policía General Francisco de Paula Santander, Bogotá D.C. 1937-2012. Bogotá D.C.: Dirección Nacional de Escuelas de Policía. Policía Nacional.

(Diciembre de 2015). La calle del Comercio de Ibagué (Colombia), 1893-1950. Un estudio sobre sus transformaciones arquitectónicas y conceptuales derivadas del modelo industrial en el tránsito de la Colonia a la República y las primeras manifestaciones del Art Déco. Dearq(17), 56-73.

doi:http://dx.doi.org/10.18389/dearq17.2015.04

(2017). El plan urbanístico Ibagué Futuro, 1935. Ibagué: Universidad del Tolima.

(2017). La superposición de cartografía histórica como método de análisis morfológico y toma de decisiones urbanísticas. Ibagué, Colombia, 1935-2016. urbe. Revista Brasileira de Gestão Urbana (Brazilian Journal of Urban Management), 9(2), 21. doi:DOI: 10.1590/2175-3369.009.002.AO10

Franco Taipe, A. S. (2014). Costuras urbanas: reconstitución de zonas con usos incompatibles a partir de espacios de uso público (Vol. 1). Quito, Ecuador: Trabajo de titulación previo a la obtención del título de arquitecto. Pontificia Universidad Católica del Ecuador. Obtenido de http://repositorio.puce.edu.ec/bitstream/handle/22000/6656/1.2.000494.pdf?sequence=4

González Calle, J. L. (2006). De la ciudad al territorio. La configuración del espacio urbano en Ibagué 18861986. Ibagué: Aquelarre.

Guarnizo, J. (20 de octubre de 2016). Así mataron el sueño de los Juegos Nacionales de Ibagué. Semana. Obtenido de http://www.semana.com/nacion/articulo/juegos-nacionales-el-desfalco-de-los-escenariosdeportivos-de-ibague/499673

Gutiérrez, R. (1921). Monografías. Tomo II. Bogotá: Imprenta Nacional de Colombia. Obtenido de Biblioteca virtual del banco de la República.: http://www.banrepcultural.org/blaavirtual/historia/dos/indice.htm

Hammill, S. (noviembre de 2016). Technical: Kintsugi. The Journal of Australian Ceramics, 55(3), 70-73.

Recuperado el 4 de enero de 2017, de http://search.informit.com.au/documentSummary; dn=473406344982684;res=IELHSS

Honorable Concejo Municipal. (14 de octubre de 1935). Acuerdo 22. Por el cual se reglamentó y dispuso la venta de los ejidos urbanos y se adoptaron los planos de la Ibagué actual y del futuro. Ibagué.

I Soler, A. L. (2006). La enseñanza de la arquitectura como poética. Vol. 14. Barcelona: Universitat Politècnica de Catalunya. Iniciativa Digital Politècnica. 
Lamarque, P. (29 de september de 2016). Reflections on the Ethics and Aesthetics of Restoration and Conservation. The British Journal of Aesthetics, 56(3), 281-299. doi:https://doi.org/10.1093/aesthj/ayw041

Mañana-Borrazás, P., Blanco-Rotea, R., \& Ayán Vila, X. (2002). Arqueotectura 1: Bases teórico-metodológicas para una Arqueología de la Arquitectura. Tapa. Traballos de Arqueoloxía e Patrimonio(25). Obtenido de http://digital.csic.es/bitstream/10261/6027/1/TAPA25.pdf

Martínez Silva, C. (2003). Historia de la forma urbana de Ibagué. En Compendio de historia de Ibagué. Ibagué: Editorial Academia de Historia, Gobernación del Tolima, Alcaldía de Ibagué. Tolima, Colombia.

(18 de abril de 2016). El plan piloto de Ibagué, 1966. (A. Francel, Entrevistador) Ibagué,

Meisel Roca, A., Ramírez, M. T., \& Jaramillo, J. (2014). Muy tarde pero rentables: Los ferrocarriles en Colombia durante el periodo 1920-1950. Cuadernos de Historia Económica y Empresarial(34), 51. Obtenido de http://www.banrep.gov.co/docum/Lectura_finanzas/pdf/chee_34.pdf

Mendoza Neira, P., \& otros. (1965). Lo mejor del ürbanismo y de la arquitectura en Colombia. Bogotá: Librería colombiana Camacho Roldán.

Molina Prieto, L. F. (julio-diciembre de 2006). Aproximación a la historia de los parques de Bogotá con énfasis en las aves que los frecuentan. Nodo, 1(1). Recuperado el 8 de octubre de 2016, de http://revistas.uan.edu.co/index.php/nodo/article/view/169/149

Moreno Martín, F. J. (enero-diciembre de 2014). Arqueología de la Arquitectura. Una visión conciliadora desde la Historia del Arte. Arqueología de la arquitectura(11), 1-19. doi:http://dx.doi.org/10.3989/arq.arqt.2014.008

Ortiz Vidales, D. (2003). 1854, Ibagué, sede del gobierno nacional. En Compendio de historia de Ibagué (pág. Capítulo XII. Tomo I). Ibagué: Academia de Historia del Tolima. Gobernación del Tolima. Alcaldía de lbagué.

Patiño, V. M. (1990). Ferrocarril del Tolima. En V. M. Patiño, Historia de la cultura material en la América equinoccial (págs. Tomo III. Vías, transportes, comunicaciones. Capítulo VIII, parte II). Bogotá: Instituto Caro y Cuervo. Obtenido de http://www.banrepcultural.org/blaavirtual/historia/equinoccial_3_transportes/cap8c1.htm

Posthuma, K. M. (2016). Kintsugi: a new framework for post-industrial transformation. College Park: Thesis for Master of Landscape, University of Maryland. Obtenido de http://drum.lib.umd.edu/bitstream/handle/1903/19100/Posthuma_umd_0117N_17756.pdf?sequence=1\&i sAllowed=y

Romero, H., Toledo, X., Órdenes, F., \& Vásquez, A. (2001). Ecología urbana y gestión ambiental sustentable de las ciudades intermedias chilenas. Ambiente y desarrollo, XVII(4), 45-51. Recuperado el 6 de marzo de 2015, de https://www.researchgate.net/profile/Alexis_Vasquez/publication/40883154_Ecologia_urbana_de_las_ci udades_intermedias_chilenas/links/0a85e533596d03cf5b000000/Ecologia-urbana-de-las-ciudadesintermedias-chilenas.pdf

Sánchez-Mateos García, J. J., Lozano Gallego, A. I., \& Sánchez Quilez, M. P. (octubre de 2015). Prevención de cicatrices hipertróficas y queloides. Enfermería Ciudad Real. Obtenido de http://www.enfermeriadeciudadreal.com/prevencion-de-cicatrices-hipertroficas-y-queloides-462.htm

Sociedad Industrial de Ingeniería y Construcciones (SIDEICO). (1935). Informe sobre el plano de lbagué, levantado en 1935. Catálogo de arrendatarios de ejidos, áreas de los lotes, etc. Ibagué: Archivo Histórico Municipal.

Talero Rodríguez, J. C. (2013). Los parques vecinales y de bolsillo en bogotá, territorio de derecho a la ciudad. Participación ciudadana y acciones territoriales. Bogotá, Colombia: Tesina de maestría, Pontificia Universidad Javeriana. Obtenido de https://repository.javeriana.edu.co:8443/bitstream/handle/10554/15646/TaleroRodriguezJohannaCarolin a2013.pdf?sequence=2\&isAllowed=y

Terminal de Transportes de Ibagué S.A. (2015). Historia. Recuperado el 20 de agosto de 2016, de Página oficial del terminal: http://terminalibague.com/inicio/acerca-de/historia/

Tibaduiza Cordero, J. R. (2015). Arquitectura religiosa moderna: Tres obras de Juvenal Moya Cadena en espacios de educación. Bogotá: Universidad Nacional de Colombia. Tesina de maestría en Historia y teoría de arte, la arquitectura y la ciudad. Obtenido de http://www.bdigital.unal.edu.co/50811/1/91071375.2015.pdf 
Tino Ramos, R. (julio-agosto de 2007). Vías, carreteras y otras calzadas: Breve historia de las mismas. Cimbra: Revista del Colegio de Ingenieros Técnicos de Obras Públicas(376), 16-25. Obtenido de http://www.citop.es/publicaciones/documentos/Cimbra376_04.pdf

Xolalpa, P. M. (2015). Los ferrocarriles mexicanos y sus cicatrices urbanas: transformación, crecimiento y generación urbana a partir del tendido del sistema ferroviario y la permanencia de los trazos. Estudios sobre conservación, restauración y museología, 1, 27-40. Obtenido de https://www.revistas.inah.gob.mx/index.php/estudiosconservacion/article/view/5443/6021 